\title{
Escorpiões: um Estudo de Caso com Estudantes do Ensino Fundamental
}

\author{
Scorpions: one Case Study with Students from Elementary School
}

\author{
Derval Gomes Ribeiro Neto*a; Yara Gomes Corrêa ${ }^{a}$; Kellen Lagares Ferreira Silva ${ }^{\text {; }}$ Carla Simone Seibert ${ }^{\mathrm{a}}$
}

aUniversidade Federal do Tocantins, Programa de Pós-Graduação Stricto Sensu em Ciências do Ambiente. TO, Brasil. .

*E-mail: derval@uft.edu.br

\begin{abstract}
Resumo
A educação ambiental pode ajudar a sensibilizar a sociedade em relação aos escorpiões, desmistificando a visão antropocêntrica, no qual o indivíduo se põe acima dos animais não humanos e da natureza. Conhecer o habitat e o comportamento dos animais pode colaborar com a conservação das espécies de escorpião, uma vez que esse conhecimento pode ajudar a respeitá-los. Grande parte da população possui um conhecimento superficial sobre os escorpiões, sendo influenciada pelo conhecimento empírico dos acidentes que estes animais proporcionam. Dessa forma, a aversão popular por animais peçonhentos, em particular pelos escorpiões, pode ser agravada por informações (e.g. casos de mortes de crianças e idosos) que pontuam especificamente o acidente, deixando de lado outras informações relevantes como a sua biologia e função na cadeia alimentar. No intuito de favorecer a relação entre ser humano e animais não humanos peçonhentos, desenvolve-se um trabalho socioambiental com estudantes de 11 a 12 anos, apresentando o modo de vida dos escorpiões, através de intervenções didático-metodológicas. Foi confeccionado um questionário contendo sete questões de fácil interpretação e resposta. As perguntas demonstraram valores significativos de dependência do pós-teste em relação à intervenção, sendo possível inferir que os sujeitos participantes possuem uma visão convencional acerca dos escorpiões, e que esta pode ser modificada com uma intervenção didático-metodológica intencional.
\end{abstract}

Palavras-chave: Sensibilização. Relação Harmônica. Animal Peçonhento.

\begin{abstract}
Environmental education can help raise society's awareness regarding scorpions, demystifying the anthropocentric view in which the individual stands above non-human animals and nature. Knowing the animals' habitat and behavior can help in the scorpion species conservation, since this knowledge can help respect them. Most of population has superficial knowledge about scorpions, being influenced by empirical accidents knowledge that these animals provide. Thus, a popular aversion to venomous animals, in particular scorpions, can be aggravated by information (for example, cases of deaths of children and the elderly) that can cause accidents, leaving aside other important information such as their biology and function in the food chain. In order to favor the relationship between human beings and venomous non-human animals, a socio environmental work was developed with students from 11 to 12 years old, presenting the scorpions' way of life through methodological didactic interventions. A questionnaire was prepared containing seven questions that are easy to interpret and answer. The questions showed significant values of dependence of the post-test in relation to the intervention, being possible to infer that the participating subjects have a conventional view about scorpions, and that this can be modified with an intentional didactic-methodological intervention.
\end{abstract}

Keywords: Tityus sp. Awareness. Harmonic Relation.

\section{Introdução}

Entre as principais causas da degradação ambiental reside o fato de que se vive segundo uma ética antropocêntrica, cujos sistemas de valores colocam o ser humano como o elemento central do universo, o que resulta em um dualismo entre homem e natureza (GRÜN, 2011). Esta visão utilitarista e fragmentada de ver a natureza está sendo agravada pelos aspectos relacionados à globalização. $\mathrm{O}$ crescimento acelerado das cidades está transformando o ambiente, resultando na frequente substituição dos espaços verdes pelo concreto. As pessoas estão perdendo o contato com a natureza por uma mudança de comportamento global, atrelada aos novos modos de vida, em função de um modelo de desenvolvimento econômico, que prioriza o capital em detrimento da natureza. As pessoas estão ficando condicionadas a espaços cada vez mais restritos para o contato com a natureza, tendo como principal fonte de lazer o uso das tecnologias, o que acarreta o aumento da apatia pela natureza, bem como pelos problemas que esta enfrenta. Assim, a natureza passa a ser apenas uma fonte de recursos, que atendam aos interesses econômicos, ocasionando mudança na relação do ser humano com a mesma (MEDEIROS et al., 2011).

Dessa forma, compreender a relação entre o ser humano e o ambiente, de maneira menos antropocêntrica é de grande relevância, e merece ser abordada de forma mais detalhada e abrangente, em toda sociedade, principalmente, nos ambientes escolares. É importante focar o estudo nas crianças, pois estas ao aprenderem que são parte da natureza e que estes animais não humanos são parte integrante da mesma biosfera em que se vive, podem se tornar adultos mais preocupados com o meio ambiente, e transmitir essas informações para a sociedade, em suas casas, famílias, amigos e vizinhos. 
As instituições de ensino já estão conscientes de que precisam trabalhar a problemática socioambiental e muitas iniciativas vêm sendo desenvolvidas em torno desta questão, no campo da educação ambiental (EA). A educação ambiental pode ser definida como um processo no qual o indivíduo obtém conhecimentos de questões ambientais, passando a ter uma nova visão sobre o meio ambiente e os animais não humanos, sobretudo os animais peçonhentos (MEDEIROS et al., 2011). Nesse sentido, a educação ambiental nas escolas pode contribuir para amenizar os problemas causados ao meio ambiente pela ação antrópica. É importante trabalhar essa temática, especialmente, nos anos iniciais, pois as crianças estão em fase de desenvolvimento cognitivo, sendo possível desenvolver sua consciência ambiental nessa etapa e traduzi-la commais possibilidade de sucesso, pois aindaestão constituindo seus hábitos e visão de mundo (CARVALHO, 2001).

Entre todos os animais, os peçonhentos são os menos compreendidos pelo ser humano, pois culturalmente causam repulsa ou medo, o que leva a população a julgar erroneamente estes animais como "dispensáveis" para o meio ambiente. Um bom exemplo é sobre o conhecimento cultural das centopeias, a aparência repulsiva culturalmente percebida pela maioria dos seres humanos é a razão pela qual as centopeias sejam consideradas perigosas e quase sempre exterminadas (COSTA NETO; RODRIGUES, 2006). O que também pode explicar a repulsa e medo pelos escorpiões, que frequentemente são eliminados pela sociedade.

Escorpiões são invertebrados peçonhentos pertencentes à classe dos aracnídeos (Arachnida), que podem habitar todos os tipos de ambientes terrestres, desde pedras cobertas de neve a desertos mais áridos, ou mesmo florestas tropicais muito úmidas (LOURENÇO; EICKSTEDT, 2009; GOPALAKRISHNAKONE et al., 2015; BICUDA, 2017; ESPOSITO, et al., 2017). É comum encontrar escorpiões nos troncos de árvores em decomposição, sob pedras, no interior de tocas, sob folhiços e em cavernas. Estes animais são mais ativos nos meses mais quentes do ano, são forrageadores e seu cardápio é amplo, mas com preferência para baratas, grilos, larvas de inseto e aranhas (LOURENÇO; EICKSTEDT, 2009). Todos os escorpiões apresentam mecanismos para inoculação de seu veneno, o que os classifica como animais peçonhentos, no entanto, nem todos causam acidentes graves ao homem (GOPALAKRISHNAKONE et al., 2015; PHILLIPS, 2018).

No Brasil, as espécies que necessitam de atenção médica para o tratamento sorológico dos acidentes por escorpiões pertencem ao gênero Tityus. O Tityus serrulatus é o responsável pela maioria dos casos de acidentes de maior gravidade, com registro de óbitos (LOURENÇO; EICKSTEDT, 2009). No Estado do Tocantins, em específico, na cidade de Palmas, 1102 acidentes por escorpiões foram relatados no intervalo de 14 anos (PARISE, 2016), sendo registradas quatro espécies de escorpiões para o município, três do gênero Tityus (OLIVEIRA et al., 2020).

O habitat natural deste aracnídeo é a savana, no entanto, esse animal se adapta facilmente para sobreviver nos lixos, esgotos e entulhos, que são comuns nas cidades (LOURENÇO; EICKSTEDT, 2009; TEIXEIRA et al., 2017). Portanto, os escorpiões estão bem adaptados às grandes cidades, pois encontram abrigo e alimento em quintais cobertos de entulhos, contudo, são predadores de insetos e outros pequenos animais que podem ser nocivos ao homem (LOURENÇO; EICKSTEDT, 2009; TEIXEIRA et al., 2017).

Grande parte da população possui um conhecimento superficial sobre os escorpiões, sendo influenciada pelo conhecimento empírico dos acidentes que estes animais proporcionam. Dessa forma, a aversão popular por animais peçonhentos, em particular pelos escorpiões, pode ser agravada por informações (e.g. casos de mortes de crianças e idosos), que pontuam especificamente o acidente, deixando de lado outras informações relevantes como a sua biologia e função na cadeia alimentar.

Portanto, este estudo teve como objetivo sensibilizar os estudantes do Ensino Fundamental sobre o modo de vida dos escorpiões e sua relação com os seres humanos, visando a preservação destes animais não humanos peçonhentos e a prevenção de acidentes, sendo o público infantil um grupo vulnerável e estratégico do ponto de vista da Educação Ambiental.

\section{Material e Métodos}

\subsection{Amostragem}

O presente estudo foi realizado em três escolas da rede pública do município de Porto Nacional, Estado do Tocantins, Brasil. As escolas foram escolhidas por sua localização no município e por possuírem duas turmas de $5^{\circ}$ ano por período: Escola Municipal Doutor Euvaldo Souza (Periurbano; Figura 1A), Escola Municipal Fanny Macedo Pereira (Periférico; Figura 1B) e Escola Municipal Padre Luso Matos (Centro; Figura 1C).

Figura 1 - Localização espacial das três escolas da rede pública do município de Porto Nacional - TO, nas quais foram realizadas as intervenções didático-metodológicas intencionais

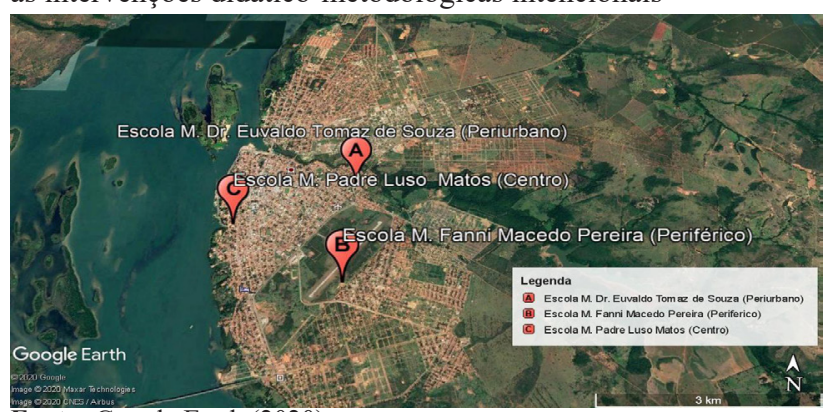

Fonte: Google Earth (2020).

Participaram da pesquisa estudantes do $5^{\circ}$ ano do Ensino Fundamental, pelo fato de, nesta fase, já terem desenvolvido a habilidade de escrita e interpretação de textos, sem perderem a capacidade da aprendizagem lúdica. A amostragem utilizada foi de 50 estudantes, estratificada por escola, com nível de 
confiança de $90 \%$ e margem de erro de $10 \%$, escolhidos aleatoriamente (Quadro 1). Não fizeram parte da amostragem os estudantes que estiveram ausentes em uma das etapas da pesquisa (primeira fase ou segunda fase).

Quadro 1 - Amostragem estratificada dos estudantes das Escolas Municipais Dr. Euvaldo Souza, Padre Luso e Fanny Macedo Pereira, Porto Nacional - TO, que participaram da pesquisa

\begin{tabular}{|c|c|c|c|c|}
\hline Escolas & $\begin{array}{c}\text { Localização no } \\
\text { município }\end{array}$ & $\begin{array}{c}\text { Total Estudantes } \\
(\mathbf{N}) *\end{array}$ & $\begin{array}{c}\text { Percentual amostral } \\
(\mathbf{\%})\end{array}$ & $\begin{array}{c}\text { Amostragem } \\
\text { Estratificada (N) }\end{array}$ \\
\hline $\begin{array}{c}\text { Escola Municipal } \\
\text { Doutor Euvaldo Souza }\end{array}$ & Periurbano & 62 & 35 & 18 \\
\hline $\begin{array}{c}\text { Escola Municipal Padre } \\
\text { Luso }\end{array}$ & Central & 64 & 36 & 18 \\
\hline $\begin{array}{c}\text { Escola Municipal Fanny } \\
\text { Macedo Pereira }\end{array}$ & Periférico & 51 & 29 & 14 \\
\hline & Total & $\mathbf{1 7 7}$ & $\mathbf{1 0 0 \%}$ & $\mathbf{5 0}$ \\
\hline
\end{tabular}

*número de estudantes matriculados na escola, em duas turmas do turno matutino, informado pela Secretaria de Educação do município de Porto Nacional - TO, em 2018.

Fonte: dados da pesquisa.

A primeira ação foi realizar o contato com os diretores das escolas para proceder a autorização e apresentar formalmente os objetivos da pesquisa. De acordo com informações fornecidas pelos diretores das escolas pesquisadas, a Lei $\mathrm{n}^{\circ}$ 10.406 , de 10 de janeiro de 2002 , artigos $5^{\circ}$ e 20 , no ato da matrícula, o pai ou responsável pelo estudante autoriza a utilização de sua imagem e/ou áudio e escrita para propagandas sem fins lucrativos e/ou pesquisas. Portanto, com a figura do diretor da unidade escolar aceitando o pedido formal, entende-se que o restante da comunidade escolar também o fez, evitando-se possíveis problemas éticos que possam ser levantados (CORRÊA; SEIBERT, 2019).

A primeira fase da pesquisa contou com a aplicação de um questionário (pré-teste), com questões de resposta fácil, para o diagnóstico do conhecimento prévio dos estudantes. Os resultados dos questionários foram utilizados para fundamentar a intervenção didático-metodológica intencional, direcionando a produção do material didático e o foco da intervenção.

A segunda fase foi a intervenção didático-metodológica intencional, realizada na escola, no turno regular das aulas, com a duração de duas horas, em dias diferentes para cada escola. Nesse período foi realizada aula expositiva, com demonstração de painel e material biológico fixado, possibilitando aos estudantes o manuseio dos escorpiões. O escorpião foi definido como animal peçonhento, foram destacadas suas características morfológicas, taxonomia, cadeia alimentar, papel do animal no ambiente, situações que propiciam o acidente, quadro clínico e ações necessárias para evitar o contato com o animal.

Após a intervenção, o questionário foi novamente aplicado (pós-teste), em que os estudantes responderam às mesmas questões do pré-teste, com o intuito de avaliar o aprendizado individual de cada participante. Para as análises foram comparados os resultados do pré-teste e pós-teste dos mesmos estudantes. A pesquisa foi realizada entre os meses de setembro e outubro de 2018.

\subsection{Estrutura do questionário}

A coleta dos resultados ocorreu pela aplicação de questionário semiestruturado, de fácil preenchimento e compreensão, conforme descrito por (MARCONI; LAKATOS, 2007). O questionário foi composto por sete questões e os dados foram analisados por categorias. A primeira categoria abordou sobre o entendimento dos estudantes em relação à taxonomia dos escorpiões, envolvendo três perguntas (P1: Você sabe o que é um aracnídeo? P2: Quais destas características são de um aracnídeo? P3: Os escorpiões são aracnídeos?). A segunda categoria foi direcionada para o conhecimento acerca da ocorrência desses na região, bem como acidentes que poderiam ter ocorrido com algum familiar ou com ele mesmo (P4: Você já viu um escorpião na região onde mora ou estuda?; P5: Você conhece alguém que já sofreu um acidente com escorpião?). A terceira categoria abordou a relação entre o escorpião e o ser humano (P6: Os escorpiões são importantes para o meio ambiente? Justifique.). E por fim, o desenho, para avaliar o conjunto de informações assimiladas pelo estudante, através da sua expressão artística (P7: Desenhe o escorpião identificando e nomeando as partes do seu corpo).

\subsection{Análise dos dados}

Os dados do pré-teste e do pós-teste foram computados em planilhas do programa Microsoft Excel 2016, os indivíduos foram numerados para proteger a identidade dos estudantes e os dados organizados seguindo as categorias acima citadas. Para testar a hipótese de interdependência foi utilizado o método Qui-Quadrado $\left(\mathrm{X}^{2}\right)$, o princípio básico do teste é comparar proporções, ou seja, possíveis divergências entre as frequências observadas e esperadas, além disso, os dados de probabilidade seguiram a correção de Yates, em que foi utilizado o software Biostat 5.0 para fazer a correção dos dados pertinentes ao método do Qui-Quadrado e a correção de Yates.

A análise dos desenhos seguiu os critérios destacados no trabalho de Marconi e Lakatos (2007), sendo classificados em: Muito Satisfatório (o animal desenhado apresentou as estruturas 
do corpo definidas, com seus respectivos nomes adequadamente identificados), Satisfatório (o animal desenhado apresentou as estruturas do corpo definidas, mas sem identificação; ou as estruturas do corpo parcialmente definidas com algumas identificações) e Insatisfatório (o animal desenhado apresentou as estruturas do corpo, parcialmente corretas ou incorretas, sem identificação das estruturas do corpo).

\section{Resultados e Discussão}

A análise do pré-teste foi fundamental para ajustar na intervenção didático-metodológica intencional, verificouse a necessidade de dar mais ênfase no papel biológico dos escorpiões e na sua interação escorpião/homem/ambiente.

As análises realizadas demonstraram probabilidade de dependência nos resultados do pós-teste em relação à intervenção didático-metodológica intencional. Isso demonstra que os estudantes obtiveram resultados positivos, após sua participação na intervenção, sendo os valores significativos para as quatro primeiras perguntas, relacionadas à taxonomia destes animais e a possibilidade de reconhecimento/encontro com esses ( $p<0,05$; Quadro 2).

Quadro 2 - Qui-quadrado de dependência entre os resultados do pós-teste em relação à intervenção metodológica sobre escorpiões, para estudantes de $5^{\circ}$ ano, em três escolas municipais de Porto Nacional - TO

\begin{tabular}{|c|c|c|}
\hline Perguntas & $\mathbf{X}^{\mathbf{2}}$ & Probabilidade \\
\hline P1 & 6.519 & 0.0255 \\
\hline P2 & 7.000 & 0.0113 \\
\hline P3 & 10.020 & 0.0036 \\
\hline P4 & 7.583 & 0.0131 \\
\hline P5 & 0.174 & 0.8691 \\
\hline P6 & 2.954 & 0.1407 \\
\hline
\end{tabular}

Fonte: Dados da pesquisa.

As três primeiras questões do instrumento para coleta de dados tinham como objetivo avaliar o aprendizado dos estudantes em relação ao grupo taxonômico dos escorpiões. Os estudantes marcaram, afirmando ou não, se os escorpiões fazem parte do grupo taxonômico dos aracnídeos. Os resultados demonstraram um acerto de $68 \%$ no pré-teste, após a intervenção metodológica este percentual aumentou para $79 \%$, demonstrando aprendizado dos estudantes (Figura 2).

Figura 2 - Percentual dos estudantes do $5^{\circ}$ ano, de três escolas municipais de Porto Nacional - TO, sobre o entendimento sobre o grupo taxonômico ao qual pertencem os escorpiões

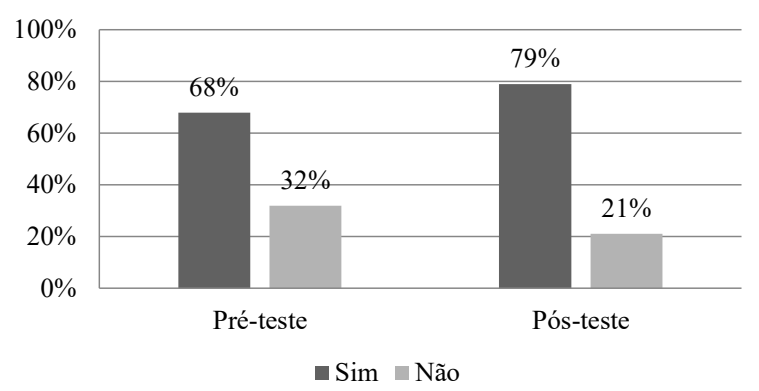

Fonte: Dados da pesquisa.
A taxonomia é a ciência da identificação, uma das mais antigas do mundo, e nasceu com a necessidade humana de classificar os seres vivos. A habilidade de classificar os seres vivos possibilitou ao ser humano identificar aqueles potencialmente letais, como por exemplo, em distinguir um animal peçonhento de um animal venenoso (BARDIN, 1979).

Atividades práticas, como as desenvolvidas na intervenção didático-metodológica, são excelentes estratégias para aprender taxonomia, o estudante mantém contato direto com o animal não humano e pode observá-lo, criando um significado, e por sua vez, aprendendo. Além disso, mesmo os estudantes que possuíam um conhecimento prévio sobre os escorpiões mudaram os conceitos relacionados a este artrópode, o que sugere que o conhecimento adquirido, em sala de aula, é assimilado (PIAGET, 1997; VEIGA, 2012). É necessário unir a teoria à prática para que o estudante construa, com a colaboração dos professores e dos conteúdos abordados, sua própria visão de mundo, mais concreta, a partir da experiência vivida na intervenção didático-metodológica.

Em complemento à temática relacionada ao conhecimento sobre a taxonomia dos escorpiões se pediu que os estudantes apontassem qual, entre as características listadas, seria a de um aracnídeo. Os resultados foram apresentados na Figura 3 e apontaram um conhecimento prévio sobre a característica marcante de um aracnídeo - a presença de "oito pernas". No pré-teste, $53 \%$ dos estudantes marcaram a característica correta, e no pós-teste esse valor aumentou para 79\%. Portanto, houve um aumento de $26 \%$ no percentual de estudantes, que passaram a compreender melhor essa questão.

Figura 3 - Características de um aracnídeo apresentadas no préteste e no pós-teste, atribuídas pelos estudantes do $5^{\circ}$ ano de três escolas municipais em Porto Nacional - TO

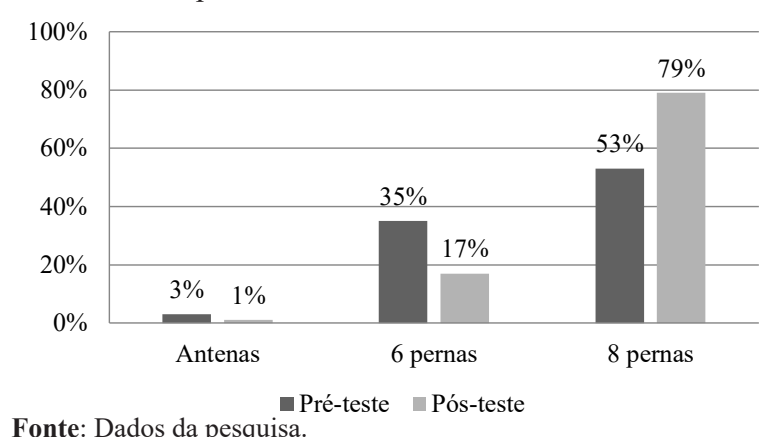

Fonte: Dados da pesquisa.

Pode-se dizer que é garantida a relação entre a teoria e a prática através do sincronismo e harmonia, da autonomia e dependência de uma em relação à outra. No entanto, é necessário compreender que esta afinidade faz parte do processo pelo qual se constrói o conhecimento (PIAGET, 1997; VEIGA, 2012).

Com relação ao bloco de questões referentes ao avistamento e acidentes por escorpiões, na região nas quais moram ou nas escolas, os estudantes das três escolas sinalizaram, positivamente, a ocorrência do contato visual com escorpiões nas proximidades de suas residências, ou na 
própria escola. Entretanto, o maior percentual de visualizações foi para os estudantes que moram na escola localizada na região periurbana do município (80\% no pós-teste; Figura 4).

O maior percentual de avistamento está relacionado também com o maior número de histórico de acidentes com esse animal. Em todas as escolas houve o registro de acidentes por escorpiões, com o próprio aluno ou com pessoas do seu convívio, com destaque novamente para a escola localizada na região periurbana da cidade ( $73 \%$ no pós-teste) (Figura 5).

Figura 4 - Percentual de visualizações de escorpião pelos estudantes, em regiões próximas das suas residências ou escolas, no município de Porto Nacional - TO

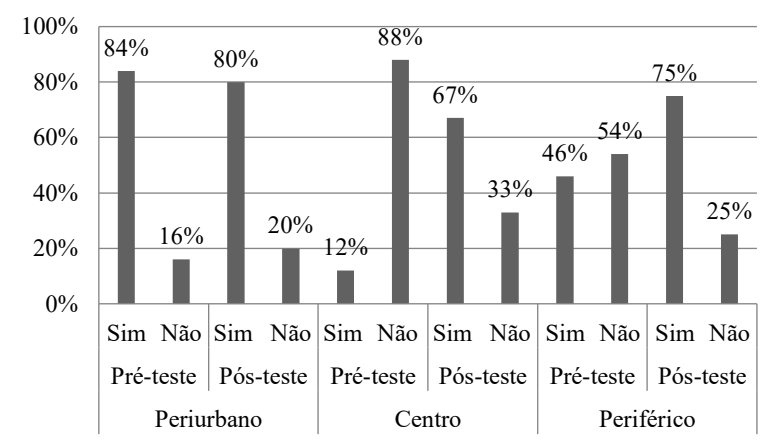

Fonte: Dados da pesquisa.

Figura 5 - Percentual de acidentes por escorpiões, em diferentes regiões da área urbana do município de Porto Nacional - TO, relatados pelos estudantes das três escolas municipais

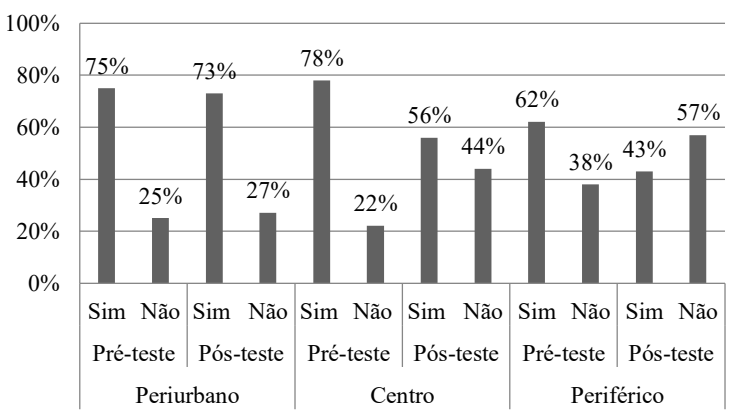

Fonte: Dados da pesquisa.

Portanto, os estudantes das escolas, que se localizam mais próximas à região da periferia do município, relataram mais encontros com os escorpiões e, consequentemente, um maior número de acidentes. $\mathrm{O}$ avistamento e acidentes com escorpiões relatados pelos estudantes da região periurbana e periférica pode se tratar de escorpiões nativos do cerrado tocantinense, algo que deve estar relacionado ao desmatamento e fixação humana recente nestes locais.

Os resultados deste trabalho demonstram que a região central do município possui pouco conhecimento sobre os escorpiões, isto pode ser evidenciado pelo número de estudantes que marcaram terem avistado escorpiões no préteste (12\%), índice que aumentou no pós-teste (68\%). Algo que também é observado no número de estudantes que relataram conhecer alguém que teria sofrido acidente por escorpião no pré-teste $(78 \%)$, o que reduziu após a intervenção didático- metodológica, no pós-teste $(56 \%)$.

Para Medeiros et al. (2011), as pessoas estão perdendo o contato com a natureza e com isso ficam condicionadas a espaços cada vez mais restritos, isso reduz a afinidade pela natureza e limita a compreensão dos elementos que a integram, como os animais não humanos.

Desde as idades iniciais se deve estimular o equilíbrio entre o homem e o ambiente, entre o animal humano e o não humano (COLOMBO; ALENCAR, 2017). O maior inimigo do homem, neste momento, é a desinformação em relação aos acidentes que estes animais podem causar, bem como as potencialidades de seu veneno. $\mathrm{O}$ que pode fazer com que o indivíduo tome decisões precipitadas frente ao encontro com os escorpiões, e no caso das crianças, sem a intervenção de um adulto, podem confundi-lo com outro artrópode, visto que durante a infância são encorajados pelos pais a matarem por esmagamento formigas, percevejos, besouros e etc. A criança se utilizando desta informação pode esmagar um escorpião, pois ela acredita que se trata de um "inseto" qualquer, e tal aproximação pode ocasionar acidente (LIMEIRA et al., 2019).

Portanto, o despreparo e a falta de conhecimento relacionados ao escorpião aumentam o risco de acidentes, visto que estes animais possuem grande praticidade em ocupar novos ambientes e agora estão se adaptando ao ambiente urbano (PHILLIPS, 2018).

A terceira temática buscou entender a relação dos estudantes com os escorpiões. Foi questionado se os escorpiões são importantes para o meio ambiente, $58 \%$ dos estudantes marcaram que sim, no pré-teste, valor que se elevou para $82 \%$ após a intervenção (Figura 6).

Figura 6 - Percentual de estudantes do $5^{\circ}$ ano de três escolas municipais de Porto Nacional - TO sobre o reconhecimento da importância ecológica dos escorpiões para o meio ambiente

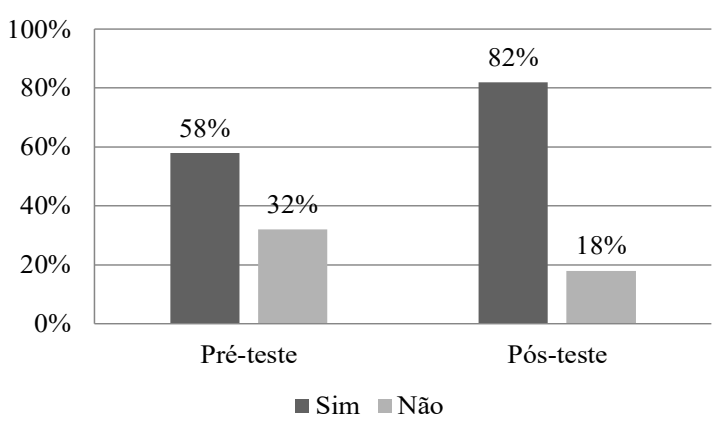

Fonte: Dados da pesquisa.

A pergunta tinha continuidade pela justificativa da resposta, seguem as justificativas dos estudantes que responderam negativamente no pré-teste:

Não. Ele é um animal muito perigoso e causa muitas tragédias (estudante A; pré-teste);

Não. Eles são atacadores e são perigosos (estudante B; préteste);

Não. Eles são perigosos para o meio ambiente (estudante C; pré-teste);

Não. Porque o meio ambiente não foi feito para ele (estudante $\mathrm{D}$; pré-teste). 
E após as intervenções, as respostas dos mesmos estudantes no pós-teste:

Sim. Ele come muitas Baratas (estudante A; pós-teste);

Sim. Eles comem baratas, e aranhas e ajudam a não ter (estudante B; pós-teste);

Sim. Porque eles ajudam a reduzir os insetos (estudante C; pós-teste);

Sim. Porque ele ajuda o meio ambiente (estudante D; préteste).

Alguns estudantes demonstraram uma preconcepção negativa sobre os escorpiões, evidenciado pelas respostas de que estes artrópodes não são importantes para o meio ambiente. Essa aversão pode estar relacionada aos acidentes sofridos, por parte dos parentes e amigos próximos, algo que corrobora com (LIMEIRA et al., 2019).

Por fim, na Figura 7 se observa a progressão dos estudantes em relação à intervenção metodológica, principalmente, após a observação e manuseio dos animais fixados. Os desenhos saíram da condição insatisfatória ( $97 \%$ no pré-teste), para satisfatório ( $59 \%$ no pós-teste) e muito satisfatório (18\% no pós-teste).

Figura 7 - Percentual de estudantes do $5^{\circ}$ ano de três escolas municipais de Porto Nacional - TO, em relação aos desenhos dos escorpiões realizados no pré-teste e no pós-teste.

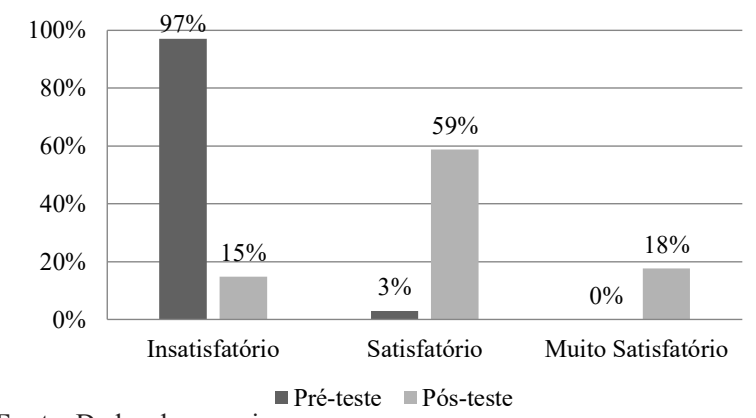

Fonte: Dados da pesquisa.

A Figura 8 traz a imagem dos desenhos realizados pelos estudantes, no pré-teste (A e C) e no pós-teste (B e D).

Figura 8 - Desenhos realizados pelos estudantes participantes da intervenção didático-metodológica, no pré-teste (A - insatisfatório e C - insatisfatório) e no pós-teste (B - muito satisfatório e D satisfatório)

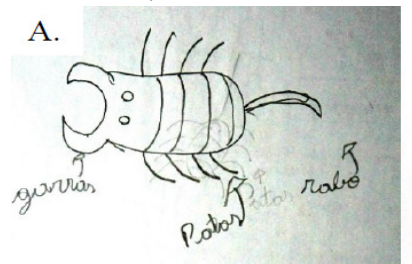

C.

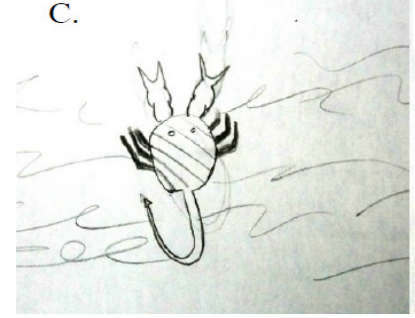

Fonte: Dados da pesquisa.

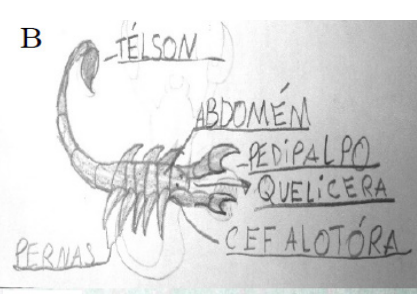

D.

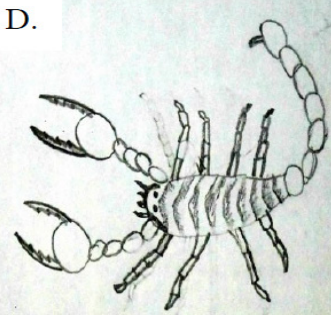

Rev. Ens. Educ. Cienc. Human., v. 21, n. 3, p. 337-344, 2020
CORREIA; PACHECO, 2015; PSILLOS; KARIOTOGLOU, 2015;) sugerem que a arte de desenhar oferece infinitos caminhos para a educação, e o ato de desenhar exige a mobilização de vários campos do conhecimento. Além disso, pode ser considerada uma ferramenta que capta a aprendizagem dos estudantes e permite a participação ativa de todos, nos seus diferentes níveis de conhecimento (ANDRADE et al., 2007).

O filósofo, médico e psicólogo francês Henri Wallon, conhecido por ser um dos grandes colaboradores para a teoria do desenvolvimento, argumenta que as trocas relacionais das crianças com os outros são fundamentais para o desenvolvimento da pessoa. As crianças nascem imersas em um mundo cultural e simbólico, no qual ficam envolvidas em um "sincretismo subjetivo". Durante esse período, de completa indiferenciação entre a criança e o ambiente humano, sua compreensão das coisas dependerá dos outros, que darão as suas ações e movimentos o formato e expressão (PIAJET, 1964). Assim, os conceitos relacionados aos escorpiões estão fortemente ligados também com o que os estudantes aprenderam no ambiente familiar, o que pode interferir quando confrontados com as informações contidas em outras fontes, como os livros, os dicionários, os jornais, as revistas, a TV e internet (LOPEZ, 2000). Além disso, a aparência incomum de alguns animais peçonhentos como os escorpiões e as centopeias, por exemplo, é culturalmente percebida pela maioria dos seres humanos, razão pela qual os animais peçonhentos são considerados perigosos, tendendo ao extermínio (BREENE, 2005; PRADA, 2008).

É necessário conscientizar as pessoas para melhorar sua relação com o ambiente que as cercam, o que torna a educação ambiental de exígua importância. Contudo, a melhor fase de desenvolvimento para mudar seus pensamentos é na infância, porque é desde pequeno que se aprende a conservar a natureza e seus integrantes. Os adultos possuem mais dificuldade para absorver novos hábitos, pois estão acostumados com os costumes antigos (MEDEIROS et al., 2011). Dessa forma, compreender a relação do ser humano com a natureza que o cerca, de maneira menos antropocêntrica, é de grande relevância e merece ser trabalhada de forma mais aprofundada e abrangente em toda sociedade, principalmente, nos ambientes escolares.

É possível evitar que os escorpiões entrem nas casas, usando protetor nas portas, telas nas janelas, fechando frestas nas paredes e cuidando o lixo, uma vez que o mesmo pode atrair baratas e outros artrópodes, que fazem parte da dieta dos escorpiões. Todos estes cuidados podem reduzir a possibilidade de contato direto com estes animais não humanos, visto que existe um crescente aumento dos acidentes com escorpiões, que está sendo registrado em todas as grandes cidades do Brasil, e isso está ocorrendo em função de condições favoráveis do ambiente (PARISE, 2016; OLIVEIRA et al., 2020). 
Durante 2 mil anos a cultura Ocidental foi e é orientada pelo pensamento antropocêntrico, uma corrente de pensamento que reconhece o homem como o centro do universo e, consequentemente, o gestor e usufrutuário do Planeta. Esta forma de visão de Mundo fez com que o homem perdesse a ligação que possuía com a natureza, fazendo com que a humanidade usufruísse de todos os recursos naturais e de todas as outras espécies animais, conforme os interesses estabelecidos por ele mesmo (COLOMBO; ALENCAR, 2017). $\mathrm{O}$ biocentrismo (ecocentrismo) se trata de uma concepção em que se preconizam os seres vivos e o meio ambiente, segundo a qual todas as formas de vida são igualmente importantes, não sendo a humanidade o centro da existência. A proposta do novo paradigma biocêntrico ou ecocêntrico surgiu em função da necessidade de mudanças no sentido de valorizar não apenas o bem-estar do homem, mas também das outras formas de seres vivos, implicando nisso o bem comum, o bem de todo o Planeta. Essa proposta não visa explorar a natureza ao bel prazer humano, mas sim, em integrar e harmonizarse com essa, visto que o conceito antropocêntrico trouxe a degradação ambiental e soma, em sua conta, várias extinções de animais e de plantas (STROPPA; VIOTTO, 2014).

Quando as crianças são informadas sobre os direitos da coexistência entre humanos e animais peçonhentos, especialmente, no mesmo ambiente em que os humanos, estas podem se transformar em adultos mais preocupados com a natureza (COLOMBO; ALENCAR, 2017;). O futuro de Planeta está atrelado ao conhecimento adquirido pelas crianças, melhor idade para o aprendizado. E a educação ambiental possui ferramentas que podem mudar o rumo das relações entre animais humanos e animais não humanos, pois pode promover valores, estimulando a aprendizagem. Como exemplo, mais compreensão em relação ao conceito biocêntrico e, menos antropocentrismo, poderão melhorar as expectativas em relação à recuperação do meio ambiente e à preservação animal, e contribuir com o resgate na melhoria das relações harmônica entre o ser humano e os animais não humanos (PRADA, 2008; MEDEIROS et al., 2011).

\section{Conclusão}

Os participantes nesta pesquisa demonstraram uma visão convencional acerca dos escorpiões, que pode ser modificada com uma intervenção didático-metodológica intencional. Há intolerância humana em relação à presença do escorpião, quer em suas residências ou em outros ambientes urbanos. Levar a informação por meio de sensibilizações pode modificar essa relação, fazendo-os entender a importância e o papel desses animais no ambiente.

Nesse contexto, a educação ambiental pode incentivar novas condutas para a sociedade, ou seja, é necessária uma transformação social, que objetiva superar as consequências geradas à natureza pelo pensamento antropocêntrico. Trabalhos como estes demonstram a necessidade de políticas públicas voltadas à orientação da população a respeito dos hábitos de vida dos escorpiões, bem como a importância deste animal não humano para o meio ambiente, o que poderá ajudar em uma relação harmônica e de prevenção de acidente

\section{Referências}

ANDRADE, A.F. et al. A Contribuição do desenho de observação no processo de ensino-aprendizagem. In: SIMPÓSIO NACIONAL DE GEOMETRIA E DESENHO TÉCNICO E VII INTERNATIONAL CONFERENCE ON GRAPHICS ENGINEERING FOR ARTS AND DESIGN, 2007, Curitiba. XVIII Simpósio Nacional de Geometria e Desenho Técnico e VII International Conference on Graphics Engineering for Arts and Design, 2007.

BARDIN, L. Análise de conteúdo. Lisboa: Edições 70, 1979.

BICUDA, C.E.M. Taxonomia. Biota Neotrop. v. 4, n.1, 2004.

BREENE, R.G. Sinister centipedes. Forum, 2005. Disponível html://www.atshq.org/articles/centipedes. Html.

CARVALHO, I.C.M. Qual educação ambiental?: Elementos para um debate sobre educação ambiental e extensão rural. Agroecol. Desenvolv. Rural Sustentável, v.2, n.2, p. 43-51, 2001.

COLOMBO, W.D.; ALENCAR, I.D.C.C. Escorpiões: um estudo de caso com alunos do Ensino Fundamental em escolas dos municípios de Santa Teresa e São Roque do Canaã, Espírito Santo, Brasil. Boletim do Museu de Biologia Mello Leitão, v. 39, p. 39-67, 2017.

CORRÊA, Y.G.; SEIBERT, C.S. Storytelling na educação ambiental para sensibilizar crianças sobre as arraias de água doce. Amb. Educ., v. 24, p. 3-31, 2019.

COSTA NETO, E.M.; RODRIGUES, R.M.F.R. Os besouros (Insecta: Coleoptera) na concepção dos moradores de Pedra Branca, Santa Terezinha, Estado da Bahia. Acta Scie. Biol. Scie., v.28, n.1, p.71-80, 2006.

ESPOSITO, L.A. et al. Systematic revision of the neotropical clubtailed scorpions, Physoctonus, Rhopalurus, and Troglorhopalurus, revalidation of Heteroctenus, and descriptions of two new genera and three new species (Buthidae, Rhopalurusinae). Bull. Am. Museum of Natural History, n. 415, 2017.

GOPALAKRISHNAKONE, P. et al. Scorpion Venoms. Hardcover: Springer Reference, 2015.

GRÜN, M. Ética e educação ambiental: a conexão necessária. Campinas: Papirus, 2011.

LIMEIRA, C.S. et al. Fatores Associados à Gravidade do Escorpionismo em Crianças e Adolescentes. In: SOMBRA, I.C.N. (Org.). Discursos, saberes e práticas da enfermagem. Ponta Grossa: Atena Editora, 2019. p.63-74,

LOPEZ, J.S. Educação na família e na escola: o que é, como se faz. São Paulo: Loyola, 2000.

LOURENÇO, W.R.; EICKSTEDT, V.R. Escorpiões de Importância Médica. In: CARDOSO, J.L.C. Animais peçonhentos no Brasil: biologia, clínica e terapêutica dos acidentes. São Paulo: Sarvier, 2009. p.198-213,

MARCONI, M.A.; LAKATOS, E.M. Metodologia cientifica: ciência e conhecimento científico, métodos científicos, teoria, hipóteses e variáveis. São Paulo: Atlas, 2007.

MEDEIROS, A.B. et al. A Importância da educação ambiental na 
escola nas séries iniciais. Rev. Fac. Montes Belos, v.4, n.1, 2011.

OLIVEIRA, R.M. et al. O escorpionismo na área urbana de Palmas - Tocantins. Rev. Bras. Geog. Méd. Saúde, v.16, p.137158, 2020.

PARISE, E.V. Vigilância e monitoramento dos acidentes por animais peçonhentos no município de Palmas, Tocantins, Brasil. Rev Bras. Geog. Méd. Saúde, v.12, n.22, p.72-87, 2016.

PHILLIPS, D. Scorpion deaths on rise in Brazil as arachnid adapts to urban life: Deaths have more than doubled as specialists warn of increasing danger for city-dwellers. The Guardian. 2018.

PIAGET, J. As formas elementares da dialética. São Paulo: Casa do Psicólogo, 1997.

PRADA, I.L.S. Animais são seres sencientes. In: TRÉZ, T. A (Org.). Instrumento animal: o uso prejudicial dos animais no ensino superior. Bauru: Canal 6, 2008. p.39.
PSILLOS, D.; KARIOTOGLOU, P. Designing developing and refining teacher-learning sequences: current perspectives and open issues. In Teaching learning sequences as innovations for science teaching and learning. 2015.

STROPPA, T.; VIOTTO, T.B. Antropocentrismo X Biocentrismo: um embate importante. Rev. Bras. Direito Animal. v.9, p.119133, 2014.

TEIXEIRA, C.S.B. et al. Práticas de Educação Ambiental na prevenção de acidentes com escorpiões na zona oeste do Rio de Janeiro - RJ, 2017. In: SIMPÓSIO DE GESTÃO AMBIENTAL E BIODIVERSIDADE, 6., 2017 Disponível em: http://itr.ufrrj. br/sigabi/anais

VEIGA, I.P.A. Nos laboratórios e oficinas escolares: a demonstração da didática. In: VEIGA, I. P. A. (Org.). Técnicas de Ensino: por que não? Campinas: Papirus, 2012. p.131-149. 